\title{
OPEN Successful pseudopregnancy of rats by short period artificial stimulation using sonic vibration
}

\author{
Marina Endo ${ }^{1}$, Shigemi Tsunoda ${ }^{3}$, Hirosuke Tawara ${ }^{3}$, Hisayuki Abe ${ }^{3}$ \& Takehito Kaneko ${ }^{1,2} \bowtie$ \\ Psuedopregnancy for embryo transfer (ET) is usually induced in rats by mating with vasectomized \\ males. Previously, we successfully induced pseudopregnancy using sonic vibration instead (Easy-ET \\ method). The transferred embryos developed normally. Conventionally, stimulation is performed \\ $7 \times 30 \mathrm{~s}$ with $5 \mathrm{~min}$ intervals at the day before ET. However, this protocol is time-consuming because \\ it imitates natural mating behavior. Here, we investigated pseudopregnancy induction with shorter \\ stimulation times. Stimulation was performed $2 \times 30 \mathrm{~s}$, with $30 \mathrm{~s}$ intervals at the proestrus stage at the \\ day before ET. Of the transferred pronuclear or two-cell embryos, $43 \%$ or $62 \%$ developed normally, \\ respectively. Furthermore, $67 \%$ or $68 \%$ of transferred pronuclear or two-cell embryos in rats at \\ estrus stage stimulated on the day of ET developed normally, respectively. Pseudopregnancy was \\ successfully induced with shorter stimulation. Furthermore, this protocol may be used to perform a \\ single-day stimulation and ET operation at the estrus stage.
}

Reproductive technologies have been used to produce new strains and maintain genetic resources in animals ${ }^{1,2}$. Embryo transfer (ET) is one such essential reproductive technology, which was developed for the efficient production of laboratory and livestock animals ${ }^{3-10}$. ET is required for the production of genetically engineered animals, generations from cryopreserved gametes, and specific pathogen-free (SPF) animal colonies. Many genetically engineered animals, including genome edited strains, have been produced as human disease models for the analysis of gene function ${ }^{11-13}$. Recently, these strains have been rapidly and easily produced by the microinjection method ${ }^{14-16}$ and a new method which could be introduced nucleases to intact embryos using electoroporation (TAKE method) using the CRISPR-Cas system ${ }^{17-19}$. Cryopreservation of embryos is helpful for the maintenance of genetic resources and regulation of animal colonies ${ }^{20}$. Furthermore, the use of SPF animals produced by ET is vital for medical research. ET has contributed to life science research that relies on these techniques in laboratory animals ${ }^{21,22}$.

Female rodents require mating stimulation to maintain their pregnancy. In general, pseudopregnancy is induced in females at the proestrus stage by mating them with vasectomized males on the day before ET is performed. Although it is standard protocol for producing pseudopregnant females, it has been complicated by pairs often failing to mate, resulting in the failed induction of pseudopregnancy. Furthermore, the breeding space and costs necessary for a sufficient number of healthy females and vasectomized males may place strain on limited lab resources. In a previous study, we successfully induced pseudopregnancy in female rats by artificial stimulation using sonic vibration instead of vasectomized males (the so-called Easy-ET method) ${ }^{23}$. The embryos which were transferred into the oviducts of pseudopregnant female rats developed into normal offspring. In the conventional Easy-ET method, pseudopregnancy was induced in females at the proestrus stage by stimulation with sonic vibration for $30 \mathrm{~s}$ performed 7 times at 5 min intervals one day before ET. However, this protocol is time consuming because it is designed to imitate natural mating behavior. In this study, we studied the possibility of inducing pseudopregnancy with a shortened period of artificial stimulation using the Easy-ET method.

\section{Results}

Table 1 shows the development of embryos transferred to rats in whom psuedopregnancy was artificially induced at the proestrus stage one day before ET. After $120 \mathrm{~s}$ of stimulation, $64 \%$ of two-cell embryos implanted successfully, and $48 \%$ developed into normal offspring. In the short-period stimulation, which was conducted for 30 s twice with a $30 \mathrm{~s}$ interval, $65 \%$ of two-cell embryos implanted, and $62 \%$ developed normally. Of pronuclear

\footnotetext{
${ }^{1}$ Division of Science and Engineering, Graduate School of Arts and Science, Iwate University, Morioka, Iwate 020-8551, Japan. 2Division of Fundamental and Applied Sciences, Graduate School of Science and Engineering, Iwate University, 4-3-5 Ueda, Morioka, Iwate 020-8551, Japan. ${ }^{3}$ Institute for Animal Reproduction, Kasumigaura, Ibaraki 300-0134, Japan. ${ }^{\varpi}$ email: takekaneko5@gmail.com
} 


\begin{tabular}{|l|l|l|l|l|l|}
\hline Stimulation & Status of embryos & No. of females & $\begin{array}{l}\text { No. of embryos } \\
\text { transferred }\end{array}$ & $\begin{array}{l}\text { No. (\%) of embryos } \\
\text { implanted }\end{array}$ & No. (\%) of offspring \\
\hline $\begin{array}{l}\text { With vasectomised } \\
\text { males }\end{array}$ & Two-cell & 3 & 60 & $42(70.0 \pm 4.1)^{\mathrm{a}}$ & $37(61.7 \pm 6.2)^{\mathrm{c}}$ \\
\hline $\begin{array}{l}30 \mathrm{~s}, 7 \text { times with 5 min } \\
\text { interval (control) }\end{array}$ & Two-cell & 3 & 60 & $38(63.3 \pm 14.3)^{\mathrm{a}}$ & $33(55.0 \pm 17.8)^{\mathrm{c}}$ \\
\hline $\begin{array}{l}120 \mathrm{~s}, 1 \text { time with no } \\
\text { interval }\end{array}$ & Two-cell & 3 & 59 & $38(64.3 \pm 8.0)^{\mathrm{a}}$ & $28(47.0 \pm 15.0)^{\mathrm{c}}$ \\
\hline \multirow{3}{*}{$\begin{array}{l}30 \mathrm{~s}, 2 \text { times with 30 s } \\
\text { interval }\end{array}$} & Two-cell & 3 & 60 & $39(65.0 \pm 8.2)^{\mathrm{a}}$ & $37(61.7 \pm 6.2)^{\mathrm{c}}$ \\
\cline { 2 - 6 } & Pronuclear & 3 & 60 & $31(51.7 \pm 22.5)^{\mathrm{a}}$ & $26(43.3 \pm 20.5)^{\mathrm{c}}$ \\
\cline { 2 - 6 } & Morula & 3 & 73 & $19(34 \pm 18.4)^{\mathrm{b}}$ & $11(20.7 \pm 14.0)^{\mathrm{d}}$ \\
\hline
\end{tabular}

Table 1. The development of embryos transferred to females who were stimulated at the proestrus stage on the day before ET. Percentages were showed as the mean \pm SD. ET embryo transfer. Significant differences at $\mathrm{P}<0.05$ : a vs. b; c vs. $\mathrm{d}$. ${ }^{*}$ Transfer $92 \mathrm{~h}$ after stimulation at the proestrus stage.

\begin{tabular}{|l|l|l|l|l|l|}
\hline \multirow{2}{*}{ Stimulation } & Status of embryos & No. of females & $\begin{array}{l}\text { No. of embryos } \\
\text { transferred }\end{array}$ & $\begin{array}{l}\text { No. (\%) of embryos } \\
\text { implanted }\end{array}$ & No. (\%) of offspring \\
\hline $\begin{array}{l}30 \mathrm{~s}, 2 \text { times, } 30 \mathrm{~s} \\
\text { interval }\end{array}$ & Two-cell & 3 & 60 & $45(75.0 \pm 4.1)$ & $41(68.3 \pm 10.3)$ \\
\cline { 2 - 6 } & Pronuclear & 3 & 60 & $43(71.7 \pm 14.3)^{\mathrm{a}}$ & $40(66.7 \pm 14.3)^{\mathrm{a}}$ \\
\hline
\end{tabular}

Table 2. The development of embryos transferred to females who were stimulated at the estrus stage on the

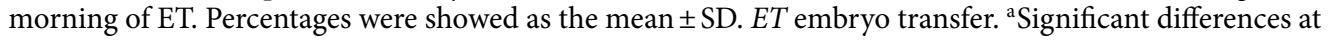
$\mathrm{P}<0.05$, compared with females stimulated at proestrus for $30 \mathrm{~s}, 2$ times with $30 \mathrm{~s}$ interval in Table 1.

stage embryos transferred to females stimulated under the same conditions, 52\% implanted and $43 \%$ developed into offspring. There were no significant differences in the development of embryos among these groups and the control group, who received $30 \mathrm{~s}$ stimulations 7 times at 5 min intervals or mated with vasectomised males $(\mathrm{P}>0.05)$. Offspring were also obtained from morulae transferred to females who were artificially induced for 30 s twice with a 30 s interval. However, these results showed significant differences compared with the development of pronuclear and two-cell embryos and control embryos $(\mathrm{P}<0.05)$.

Table 2 shows the development of embryos transferred to females in whom psuedopregnancy was artificially induced at the estrus stage on the morning of ET. After stimulation for $30 \mathrm{~s}$ twice with a $30 \mathrm{~s}$ interval, $75 \%$ of two-cell embryos implanted normally and $68 \%$ developed into normal offspring. These results showed no significant differences compared with the development of embryos transferred to females who were stimulated at the proestrus stage (Table 1; $\mathrm{P}>0.05$ ). Of the fresh pronuclear stage embryos transferred to females stimulated under the same conditions, $72 \%$ implanted successfull and $67 \%$ developed normally. These results were significantly higher compared with those of pronuclear stage embryos transferred to females who were stimulated at the proestrus stage (Table 1).

\section{Discussion}

In this study, we successfully induced pseudopregnancy in rats using a shortened Easy-ET method, wherein psuedopregnancy was artificially stimulated using sonic vibration. In the conventional Easy-ET method, pseudopregnancy is induced in females at the proestrus stage by sonic vibration for $30 \mathrm{~s}$ per stimulation 7 times in 5 min intervals on the day before ET. However, this protocol takes time because it is designed to imitate natural mating behavior. Here, we successfully induced pseudopregnancy in rats by stimulation for $30 \mathrm{~s}$ twice with a $30 \mathrm{~s}$ interval. The pronuclear and two-cell embryos transferred into the oviducts of females who underwent induced pseudopregnancy by short-period stimulation, and these embryos developed into normal offspring (Table 1).

These results show that this shorter induction method decreases the operation time for inducing pseudopregnancy by artificial stimulation. The stimulation and interval times in the conventional protocol was set based on the results obtained by monitoring copulatory behavior ${ }^{23}$. However, the results of this study showed that pseudopregnancy could be induced without imitating copulatory behavior. It was demonstrated that pseudopregnancy could be sufficiently induced with a shorter stimulation time than actual copulatory behavior.

Although the offspring were obtained from the morulae after transfer to females with artificially induced pseudopregnancy, their development was lower than that of pronuclear and two-cell embryos (Table 1). The reason for this is unknown from these results. The time of transplantation in morulae was obviously different from the transfer of pronuclear and two-cell embryos, because the morulae were transferred into the uterus of females at $92 \mathrm{~h}$ after stimulation at the proestrus stage. It is known that the sensitive interaction between the development of embryos and female conditions for embryo implantation, called the implantation window, affects the success rate of implantation ${ }^{24}$. Furthermore, it is thought that the uteri of mice show limited implantation capacity $^{25}$. Further studies on optimizing the stimulation conditions for females or the culture conditions of embryos in vitro are required to improve the success rate of morula transfer. 


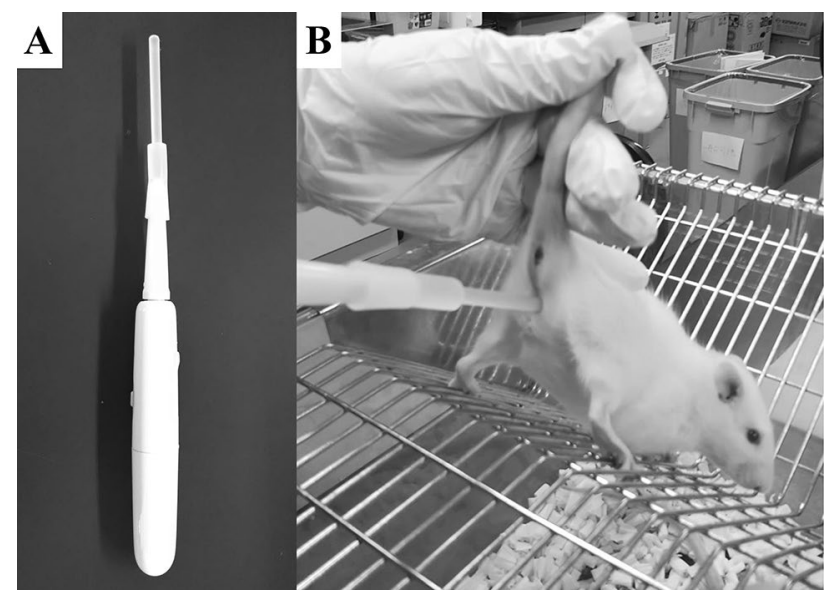

Figure 1. Sonic vibrator (A). Probe were inserted in the vagina of female (B).

In this study, high rates of successful development were observed in the transfer of pronuclear embryos (Table 1). In general, developmental rates were stable when two-cell embryos were transferred to females who underwent induced pseudopregnancy the day before ET. This study demonstrated that pronuclear stage embryos that were transferred on the same day as pseudopregnancy induction developed into normal offspring without significant differences. Furthermore, this study examined the development of embryos transferred to females, which induced pseudopregnancy in the morning of ET (Table 2). No significant differences were observed in the development of the offspring of two-cell embryos transferred one day before stimulation or on the same day of stimulation. Surprisingly, successful development of pronuclear stage embryos transferred to females who were induced on the morning of ET was significantly higher than that of pronuclear embryos transferred to females induced the day before ET. Genome-edited animals are generally produced by genomic modification of pronuclear stage embryos using microinjection and the TAKE method ${ }^{16,19}$. These results indicate that the induction of pseudopregnant females, genome editing of pronuclear stage embryos, and embryo transfer can be carried out during a one-day operation. The establishment of a one-day operation greatly contributed to the efficient production of new animal strains.

In this study, we successfully induced artificial pseudopregnancy in female rats by short-period stimulation using sonic vibration. The pronuclear and two-cell embryos that were transferred into the oviducts of these pseudopregnant female rats developed into normal offspring. This protocol is expected to be useful for the production of genome-edited animal ${ }^{26-28}$, production of generations from cryopreserved gametes ${ }^{29,30}$, and specific pathogen-free (SPF) animal colonies. Furthermore, this improved procedure could reduce the need for large breeding spaces and pain during treatment to induce pseudopregnancy and contribute to animal welfare and 3Rs.

\section{Methods}

Animals. Iar:Wistar-Imamichi rats (Institute for Animal Reproduction, Ibaraki, Japan) aged 9-14 weeks were used for embryo collection and subsequent embryo transfer. The breeding conditions were as follows: room temperature, $23 \pm 3{ }^{\circ} \mathrm{C}$; humidity, $50 \% \pm 10 \%$; and lighting from 07:00 to 19:00. All animal care and procedures performed in this study were reported in accordance with ARRIVE guidelines, and were approved by the Animal Research Committee of Iwate University and the Institute for Animal Reproduction. All methods were carried out in accordance with relevant guidelines and regulations.

Embryo collection. Females were superovulated with an intraperitoneal injection of $300 \mathrm{IU} / \mathrm{kg}$ pregnant mare serum gonadotropin (PMSG; ASKA Animal Health Co., Ltd., Tokyo, Japan), and 300 IU/kg human chorionic gonadotropin (hCG; ASKA Animal Health Co., Ltd.) $48 \mathrm{~h}$ after the injection of PMSG. The females were then mated with mature males overnight. The presence of plugs confirmed the occurrence of mating. At $24 \mathrm{~h}$ after the injection of hCG, pronuclear stage embryos were collected by flushing the oviducts with modified Krebs-Ringer bicarbonate (mKRB) medium ${ }^{31,32}$. Some embryos were then cultured to the two-cell and morula stages.

Artificial pseudopregnancy of females by easy-ET method. The estrus cycles of females were estimated by observing vaginal secretions stained with $10 \%$ Giemsa stain solution on glass slides.

Artificial stimulation for induction of pseudopregnancy was carried out in females at the proestrus stage at 16:00-17:00 on the day before ET. A self-made sonic vibrator (Fig. 1A) ${ }^{23}$ was used for artificial stimulation. The probe of the vibrator was inserted into the vagina of the female. The tip of the probe was then gently pressed into the cervical canal (Fig. 1B). Stimulation at $0.75 \mathrm{~W}$ power and 20,000 times per min vibration was carried out for $120 \mathrm{~s}$ once, or $30 \mathrm{~s}$ twice with $30 \mathrm{~s}$ intervals.

In another operation, psuedopregnancy was induced in females at the estrus stage at 9:00-10:00 on the morning of ET. These females were stimulated using the same vibrator for $30 \mathrm{~s}$ twice at $30 \mathrm{~s}$ interval. Females at the proestrus stage were stimulated for $30 \mathrm{~s}$ per stimulation seven times in 5 min intervals on the day before 
ET for control. The embryos transfer using pseudopregnant females mated with vasectomised males were also carried out as controls.

Embryo transfer. The two-cell embryos were transferred into the oviducts of females at $17-19 \mathrm{~h}$ after artificial stimulation for $120 \mathrm{~s}$ at the proestrus stage and control. The pronuclear stage and two-cell embryos were transferred into the oviducts of females at 22-24 h and 17-19 h, respectively, after artificial stimulation for $30 \mathrm{~s}$ twice, at $30 \mathrm{~s}$ interval at the proestrus stage. The embryos that developed into morulae were transferred into the uteri of females $92 \mathrm{~h}$ after stimulation at the proestrus stage.

The pronuclear and two-cell embryos were transferred into the oviducts of females at 5-6 h and $1-2 \mathrm{~h}$ after artificial stimulation for $30 \mathrm{~s}$ twice with a $30 \mathrm{~s}$ interval at the estrus stage.

The implantation sites were observed and offspring were counted at $18 \mathrm{~d}$ after embryo transfer.

Data analysis. Data were analyzed using the chi-square test followed by a multiple comparison test using Ryan's method.

\section{Data availability}

The authors declare that the data supporting the findings of this study are available within the paper.

Received: 12 October 2021; Accepted: 4 January 2022

Published online: 24 January 2022

\section{References}

1. Benson, J. D., Woods, E. J., Walters, E. M. \& Critser, J. K. The cryobiology of spermatozoa. Theriogenology 78, 1682-1699 (2012).

2. Agca, Y. Genome resource banking of biomedically important laboratory animals. Theriogenology 78, 1653-1665 (2012).

3. Heape, W. Preliminary note on the transplantation and growth of mammalian ova within a uterine foster-mother. Proc. Roy. Soc. Lond. 48, 457-458 (1890).

4. Chang, M. C. Development and fate of transferred rabbit ova or blastocysts in relation to the ovulation time of recipients. J. Exp. Zool. 114, 197-216 (1950).

5. Maurer, R.R., Onuma, H. \& Foote, RH. Viability of cultured and transferred rabbit embryos. J. Reprod. Fertil. 21, 417-422 (1970).

6. McLaren, A. \& Michie, D. Studies on the transfer of fertilized mouse eggs to uterine foster mothers. I. Factors affecting the implantation and survival of native and transferred eggs. J. Exp. Biol. 33, 394-416 (1956).

7. Tarkowski, A. K. Experimental studies on regulation in the development of isolated blastomeres of mouse eggs. Acta Theriol. 3 , 191-267 (1959).

8. Nicholas, J. S. Development of transplanted rat eggs. Proc. Soc. Exp. Biol. Med. 30, 1111-1113 (1933).

9. Noyes, R. W. \& Dickmann, Z. Survival of ova transferred into the oviduct of the rat. Fertil. Steril. 12, 67-79 (1961).

10. Betteridge, K. J. A history of farm animal embryo transfer and some associated techniques. Anim. Reprod. Sci. 79, 203-244 (2003).

11. Jacob, H. Functional genomics and rat models. Genome Res. 9, 1013-1016 (1999).

12. Aitman, T. J. et al. Progress and prospects in rat genetics: A community view. Nat. Genet. 40, 516-522 (2008)

13. Meek, S., Mashimo, T. \& Burdon, T. From engineering to editing the rat genome. Mamm. Genome 28, 302-314 (2017).

14. Li, D. et al. Heritable gene targeting in the mouse and rat using a CRISPR-Cas system. Nat. Biotechnol. 31, 681-683 (2003).

15. Li, W., Teng, F., Li, T. \& Zhou, Q. Simultaneous generation and germline transmission of multiple gene mutations in rat using CRISPR-Cas systems. Nat. Biotechnol. 31, 684-686 (2003).

16. Kaneko, T. \& Mashimo, T. Creating knockout and knockin rodents using engineered endonucleases via direct embryo injection. Methods Mol. Biol. 1239, 307-315 (2015).

17. Kaneko, T., Sakuma, T., Yamamoto, T. \& Mashimo, T. Simple knockout by electroporation of engineered endonucleases into intact rat embryos. Sci. Rep. 4, 6382 (2014).

18. Kaneko, T. \& Mashimo, T. Simple genome editing of rodent intact embryos by electroporation. PLoS One 10, e0142755 (2015).

19. Kaneko, T. Genome editing in mouse and rat by electroporation. Methods Mol. Biol. 1630, 81-89 (2017).

20. Mobraaten, L. E. Mouse embryo cryobanking. J. In Vitro Fert. Embryo Transf. 3, 28-32 (1986).

21. Reetz, I. C., Wullenweber-Schmidt, M., Kraft, V. \& Hedrich, H. J. Rederivation of inbred strains of mice by means of embryo transfer. Lab. Anim. Sci. 38, 696-701 (1988).

22. Van Keuren, M. L. \& Saunders, T. L. Rederivation of transgenic and gene-targeted mice by embryo transfer. Transgenic Res. 13, 363-371 (2004).

23. Kaneko, T., Endo, M., Tsunoda, S., Nakagawa, Y. \& Abe, H. Simple induction of pseudopregnancy by artificial stimulation using a sonic vibration in rats. Sci. Rep. 10, 2729 (2020).

24. Carson, D. D. et al. Embryo implantation. Dev. Biol. 223, 217-237 (2000).

25. Paria, B. C., Huet-Hudson, Y. M. \& Dey, S. K. Blastocyst's state of activity determines the "window" of implantation in the receptive mouse uterus. Proc. Natl. Acad. Sci. USA 90, 10159-10162 (1993).

26. Wake, Y. \& Kaneko, T. Production of genome-edited mice by visualization of nucleases introduced into the embryos using electroporation. J. Reprod. Dev. 66, 469-473 (2020).

27. Kaneko, T. \& Nakagawa, Y. Genome editing of rodents by electroporation of CRISPR/Cas9 into frozen-warmed pronuclear-stage embryos. Cryobiology 92, 231-234 (2020).

28. Nakagawa, Y. \& Kaneko, T. Rapid and efficient production of genome-edited animals by electroporation into oocytes injected with frozen or freeze-dried sperm. Cryobiology 90, 71-74 (2019).

29. Taketsuru, H. \& Kaneko, T. Efficient collection and cryopreservation of embryos in F344 strain inbred rats. Cryobiology 67, 230-234 (2013).

30. Taketsuru, H. \& Kaneko, T. Tolerance to vitrification of rat embryos at various developmental stages. Cryobiology 84, 1-3 (2018).

31. Miyamoto, H., Toyoda, Y. \& Chang, M. C. Effect of hydrogen-ion concentration on in vitro fertilization of mouse, golden hamster, and rat eggs. Biol. Reprod. 10, 487-493 (1974).

32. Toyoda, Y. \& Chang, M. C. Fertilization of rat eggs in vitro by epididymal spermatozoa and the development of eggs following transfer. J. Reprod. Fertil. 36, 9-22 (1974).

\section{Acknowledgements}

This work was supported by Grants-in-Aid for Scientific Research from the Japan Society for the Promotion of Science (21K05996, 20H00420), funds from the NIBB Collaborative Research Program (19-907, 20-709, 
21-604) and the Environment Research and Technology Development Fund of the Environmental Restoration and Conservation Agency of Japan (4-2101).

\section{Author contributions}

T.K. designed the work, analyzed the data, and wrote the manuscript. M.E., S.T., H.T., and H.A. performed the experiments. All authors have reviewed the manuscript before submission.

\section{Funding}

This article was funded by Japan Society for the Promotion of Science (Grant no. 21K05996, 20H00420), NIBB Collaborative Research Program (Grant nos. 19-907, 20-709, 21-604) and Environmental Restoration and Conservation Agency of Japan (Grant no. 4-2101).

\section{Competing interests}

Iwate University and Institute for Animal Reproduction have applied for a patent describing this method including vibrator (patent application no. 2020-77576). T. K. is listed as one of the inventors of the patent and Iwate University will receive part of the revenue that it may generate. Other authors declare no competing interests.

\section{Additional information}

Correspondence and requests for materials should be addressed to T.K.

Reprints and permissions information is available at www.nature.com/reprints.

Publisher's note Springer Nature remains neutral with regard to jurisdictional claims in published maps and institutional affiliations.

(c) (i) Open Access This article is licensed under a Creative Commons Attribution 4.0 International License, which permits use, sharing, adaptation, distribution and reproduction in any medium or format, as long as you give appropriate credit to the original author(s) and the source, provide a link to the Creative Commons licence, and indicate if changes were made. The images or other third party material in this article are included in the article's Creative Commons licence, unless indicated otherwise in a credit line to the material. If material is not included in the article's Creative Commons licence and your intended use is not permitted by statutory regulation or exceeds the permitted use, you will need to obtain permission directly from the copyright holder. To view a copy of this licence, visit http://creativecommons.org/licenses/by/4.0/.

(c) The Author(s) 2022 